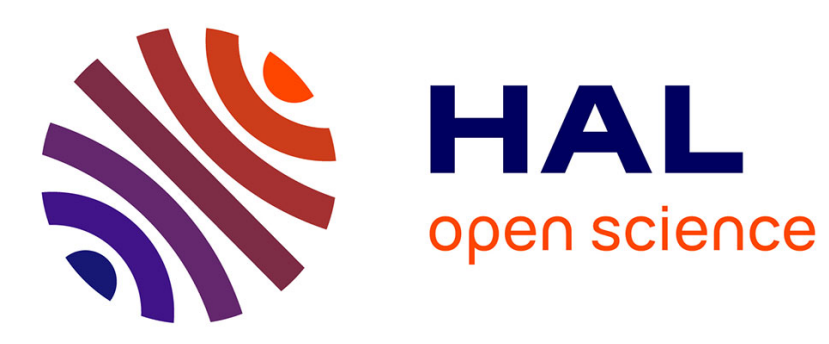

\title{
Formaldehyde-Free Polybenzoxazines for High Performance Thermosets
}

Romain Tavernier, Lérys Granado, Gabriel Foyer, Ghislain David, Sylvain Caillol

\section{- To cite this version:}

Romain Tavernier, Lérys Granado, Gabriel Foyer, Ghislain David, Sylvain Caillol. Formaldehyde-Free Polybenzoxazines for High Performance Thermosets. Macromolecules, 2020, 53 (7), pp.2557-2567. 10.1021/acs.macromol.0c00192 . hal-02546388

\section{HAL Id: hal-02546388 https://hal.science/hal-02546388}

Submitted on 7 May 2020

HAL is a multi-disciplinary open access archive for the deposit and dissemination of scientific research documents, whether they are published or not. The documents may come from teaching and research institutions in France or abroad, or from public or private research centers.
L'archive ouverte pluridisciplinaire HAL, est destinée au dépôt et à la diffusion de documents scientifiques de niveau recherche, publiés ou non, émanant des établissements d'enseignement et de recherche français ou étrangers, des laboratoires publics ou privés. 
This document is confidential and is proprietary to the American Chemical Society and its authors. Do not copy or disclose without written permission. If you have received this item in error, notify the sender and delete all copies.

\section{Formaldehyde-free polybenzoxazines for high performance thermosets}

\begin{tabular}{|c|c|}
\hline Journal: & Macromolecules \\
\hline Manuscript ID & ma-2020-00192c.R1 \\
\hline Manuscript Type: & Article \\
\hline $\begin{array}{r}\text { Date Submitted by the } \\
\text { Author: }\end{array}$ & $\mathrm{n} / \mathrm{a}$ \\
\hline Complete List of Authors: & $\begin{array}{l}\text { Tavernier, Romain; Ecole Nationale Superieure de Chimie de Montpellier, } \\
\text { Granado, Lerys; ICGM, } \\
\text { Foyer, Gabriel; ArianeGroup } \\
\text { David, Ghislain; Ecole Nationale Superieure de Chimie de Montpellier, } \\
\text { Caillol, Sylvain; Institut Charles Gerhardt de Montpellier }\end{array}$ \\
\hline
\end{tabular}

\section{SCHOLARONE \\ Manuscripts}



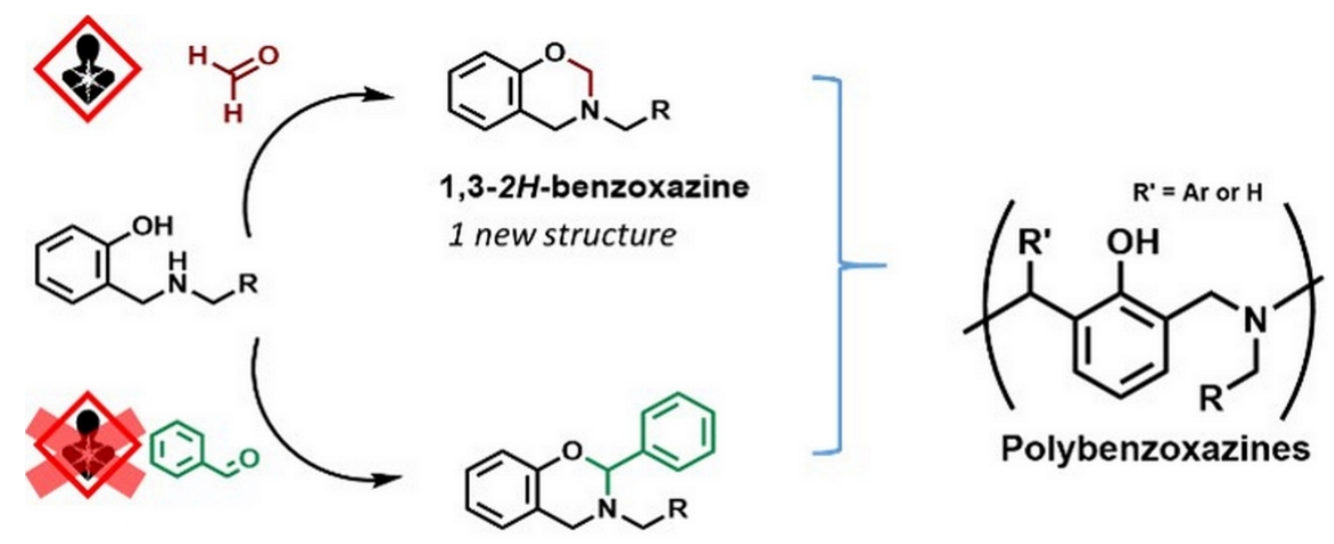

\section{1,3-2-substituted-benzoxazine}

3 new structures

$148 \times 76 \mathrm{~mm}(600 \times 600 \mathrm{DPI})$ 


\title{
Formaldehyde-free polybenzoxazines for high performance thermosets
}

\author{
Romain Taverniera, Lérys Granadoa, Gabriel Foyer ${ }^{b}$, Ghislain Davida, Sylvain Caillola,* \\ aCGM, Univ. Montpellier, CNRS, ENSCM, Montpellier, France \\ ${ }^{b}$ ArianeGroup, Rue de Touban, 33185 Le Haillan, France \\ *corresponding author : Sylvain Caillol, Institut Charles Gerhardt, 240 Av Prof Emile Jeanbrau, 34296 \\ Montpellier Cedex 5, sylvain.caillol@enscm.fr
}

\begin{abstract}
We report the synthesis and ring-opening polymerization of new formaldehyde-free benzoxazines. The polybenzoxazines obtained displayed high thermal stability and high char yields. Data from literature combined with our analyses by differential scanning calorimetry and thermogravimetric analyses gave deeper understanding about the use of aromatic aldehydes instead of formaldehyde for the generation of polybenzoxazines. Using pyrolysis coupled with gas chromatography/mass spectrometry (Py-GC/MS) at different temperatures, we provided qualitative data to propose some polymerization and degradation mechanisms associated with these new structures. A dialdehyde was also used for the first time in order to obtain difunctional monomers, instead of using diamines or bisphenols. Interestingly, we demonstrated that formaldehyde, which is a CMR (Carcinogenic, Mutagenic and/or Reprotoxic) substance, could be avoided for the synthesis of polybenzoxazines without any loss of thermal performance. Finally, some interesting structure-properties relationships are herein discussed. Particularly, the use of benzyl amines, rather than aromatic amines, was found to significantly increase the char yields.
\end{abstract}

\section{Introduction}

During the last 30 years, research on polybenzoxazine has been growing fast, at the forefront of the innovations in phenolic thermosets. Compared to the century old phenol-formaldehyde, benzoxazine chemistry presents several advantages among them we find condensation-free cross-linking, a near zero volumetric shrinkage, high glass transition temperature, high degradation temperatures and high char yields. ${ }^{1-3}$ In contrast, their industrialization suffers from the inconvenient crystallinity of the monomers/prepolymers and the requirement of elevated temperatures to achieve the cross-linking of the thermoset during curing. It is believed that these issues being solved, polybenzoxazines can find many applications in cutting-edge technologies, such as chelation agents for metal recovery in aqueous media, ${ }^{4}$ high performance composites, ${ }^{5}$ spatial radiation insulating shields, ${ }^{6}$ porous materials for $\mathrm{CO}_{2}$ capture, ${ }^{7}$ anti-corrosion coatings ${ }^{8}$ or even self-healing and shape-memory polymers. ${ }^{9}$

Since the first benzoxazine synthesis, performed by Holly and Cope, ${ }^{10}$ benzoxazine chemistry has shown high versatility. Traditionally, obtained from the condensation of formaldehyde between a phenolic moiety and a primary amine, benzoxazine synthesis is therefore compatible with a wide range of chemical functionalities. Andreu et al. have identified three main pathways to obtain 1,3-benzoxazines architectures, ${ }^{11}$ two of them appearing to be predominant in the articles published nowadays. ${ }^{12-15}$ The one-pot method is the most practical one, used either in bulk or in solution, and developed for the most reactive amines. The 3-step method is used with less reactive amines, or to prevent the formation of oligomers by using salicylaldehyde to form an imine. ${ }^{16,17}$ A secondary amine is then obtained by imine reduction, forming the first part of the heterocycle. The last step 
consists in the formation of the oxazine ring by reacting formaldehyde with the phenol moiety and the secondary amine.

These synthetic methods were used to obtain a wide range of benzoxazine monomers, which allowed researchers to find the parameters having an influence on thermal properties of polybenzoxazine networks. For instance, electron-withdrawing groups on the phenol moiety have a strong effect on the ring-opening temperature. High aromatic content and high crosslink densities are required to get high degradation temperatures and improved char yields. For instance, Endo and Nalakathu Kolanadiyil investigated the influence of the oxazine ring number in benzoxazine monomers on their thermal stabilities, evidencing that a higher content of oxazine rings improves thermal stability of cured thermosets. ${ }^{18}$ However, an increase of the monomers functionality leads to a decrease of the reactivity, thus requiring higher curing temperatures. The design of benzoxazine monomers is therefore crucial to reach the desired thermal properties.

One of the biggest drawback of benzoxazine is the use of the harmful formaldehyde in the synthesis of monomers. Formaldehyde substitution is challenging since the use of aliphatic aldehydes is detrimental to the final thermal stability. So far, only two examples of formaldehyde-free 1,3-benzoxazines have been published, for thermoset applications. Ohashi et al. were the first team to report the synthesis of two 2-substituted benzoxazines using salicylaldehyde route ${ }^{19}$ namely, a monobenzoxazine based on benzaldehyde and aniline and a bisbenzoxazine (one monomer with two oxazine rings) with the $p$-phenylenediamine. The authors reported good thermal performances after curing, with rather high char yields ( $25 \%$ and $48 \%$, respectively). More recently, Pereira et al. reported the polymerization of two hydrogenated cardanol-based benzoxazines using benzaldehyde and valeraldehyde, but the preparation of the starting phenolic compounds still required the use of formaldehyde and their thermal performances were rather limited. ${ }^{20}$ Overall, we found a lack in the literature of alternatives to formaldehyde for synthesizing more sustainable benzoxazines with high thermal performances.

In response, we aim in this work at providing new formaldehyde-free benzoxazines structures using the aforementioned salicylaldehyde reaction pathway. Monofunctional benzaldehyde and benzylamine are reacted to produce monobenzoxazines. Moreover, difunctional terephthalaldehyde (TPA) and meta-xylylenediamine (mXDA) are employed to synthesize bisbenzoxazines. We propose herein a systematic study on the effect of the aromatic aldehyde and amine, and their functionality, on the syntheses and properties, in close comparison with previous literature data. We provide a qualitative analysis for the determination of polymerization mechanisms, especially by analyzing the released compounds during polymerization with a gas chromatography technique. Finally, we show that these new benzoxazines display very high thermal performances, showcasing one important benefit of the formaldehyde substitution.

\section{Experimental Section}

Materials. Salicylaldehyde and terephthalaldehyde were purchased from TCl. Benzylamine, paraformaldehyde, meta-xylylenediamine (m-XDA), sodium borohydride, and benzaldehyde were purchased from Sigma-Aldrich. Anhydrous magnesium sulphate, toluene, ethyl acetate, dichloromethane, cyclohexane and methanol were purchased from VWR. Deuterated chloroform was purchased from Eurisotop. All solvents and reagents were used without further purification.

\section{Synthesis of salicylamines}

Synthesis of 2-((benzylamino)methyl)phenol (Scheme 1, A and B, $R_{1}=B z$ ) 
$11.40 \mathrm{~g}$ of salicylaldehyde were dissolved in $50 \mathrm{~mL}$ of methanol. $10.0 \mathrm{~g}$ of benzylamine were added to the mixture and then refluxed for $2 \mathrm{~h}$. After cooling to room temperature, solvent was removed under reduced pressure. Corresponding imine was isolated for characterization purpose. Reduction was then performed by dissolving $10.52 \mathrm{~g}$ of the imine in $50 \mathrm{~mL}$ of methanol, and $3.68 \mathrm{~g}$ of sodium borohydride were added in small portions, at $0{ }^{\circ} \mathrm{C}$, in order to limit foaming. After complete addition of the sodium borohydride, reaction mixture was heated to reflux for another $2 \mathrm{~h}$. After cooling to room temperature, the reaction mixture was quenched by precipitation in distilled water. The resulting viscous amine was then recovered by liquid-liquid extraction with ethyl acetate, organic phase was dried over magnesium sulfate and solvent was removed under reduced pressure to afford the desired product. $15.30 \mathrm{~g}$ of yellow oil was recovered. Yield $=77 \%$.

HRMS $\left(\mathrm{m} / \mathrm{z}\right.$, positive mode, $\left.[\mathrm{M}+\mathrm{H}]^{+}\right): \mathrm{C}_{14} \mathrm{H}_{16} \mathrm{NO}$; calculated 214.1226, found 214.1236.

Synthesis of 2,2'-(((1,3-phenylenebis(methylene))bis(azanediyl))bis(methylene))diphenol (Scheme 1, A and B, R $=\mathrm{m}$-xylylene)

$17.91 \mathrm{~g}$ of salicylaldehyde were dissolved in $50 \mathrm{~mL}$ of methanol. $10.03 \mathrm{~g}$ of $\mathrm{m}$-XDA were added to the mixture and then refluxed for $2 \mathrm{~h}$. After cooling to room temperature, solvent was removed under reduced pressure. Corresponding imine was isolated for characterization purpose. Reduction was then performed by dissolving the imine in $50 \mathrm{~mL}$ of methanol, and $5.61 \mathrm{~g}$ of sodium borohydride were added in small portions, at $0{ }^{\circ} \mathrm{C}$, in order to control the foaming. After complete addition of the sodium borohydride, reaction mixture was heated to reflux for another $2 \mathrm{~h}$. After cooling to room temperature, the reaction mixture was quenched by precipitation in distilled water. The resulting viscous amine was then recovered by liquid-liquid extraction with ethyl acetate, organic phase was dried over magnesium sulfate and solvent was removed under reduced pressure to afford the desired product. $24.81 \mathrm{~g}$ of a viscous pale-yellow oil were recovered that further crystallized as a white solid. Yield $=97 \%$.

HRMS ( $m / z$, positive mode, $\left.[\mathrm{M}+\mathrm{H}]^{+}\right): \mathrm{C}_{22} \mathrm{H}_{25} \mathrm{~N}_{2} \mathrm{O}_{2}$; calculated 349.1911, found 349.1927.

\section{Synthesis of benzoxazine monomers.}

Synthesis of 1,3-bis((2H-benzo[e][1,3]oxazin-3(4H)-yl)methyl)benzene (Ph-mxda) (Scheme 1, C, $\mathrm{R}_{1}=$ m-xylylene and $\mathrm{R}_{2}=\mathrm{H}$ )

$1.03 \mathrm{~g}$ of 2,2'-(((1,3-phenylenebis(methylene))bis(azanediyl))bis(methylene))diphenol were dissolved in $20 \mathrm{~mL}$ of toluene. $0.17 \mathrm{~g}$ of paraformaldehyde were added to the mixture, and then refluxed for $2 \mathrm{~h}$ with a Dean-Stark apparatus. After cooling to room temperature, solvent was removed under reduced pressure. Product was recovered as a transparent viscous oil. Yield $>99 \%$.

HRMS $\left(m / z\right.$, positive mode, $\left.[\mathrm{M}+\mathrm{H}]^{+}\right): \mathrm{C}_{24} \mathrm{H}_{25} \mathrm{~N}_{2} \mathrm{O}_{2}$; calculated 373.1911, found 373.1918. NMR ${ }^{1} \mathrm{H}\left(\mathrm{CDCl}_{3}, 7.26\right.$ ppm) $\delta=7.38(1 \mathrm{H}), 7.27-7.35(\mathrm{~m}, 3 \mathrm{H}), 7.16(\mathrm{t}, 2 \mathrm{H}), 6.82-6.95(\mathrm{~m}, 6 \mathrm{H}), 4.89(\mathrm{~s}, 2 \mathrm{H}), 3.98(\mathrm{~s}, 2 \mathrm{H}), 3.94(\mathrm{~s}, 2 \mathrm{H}) . \mathrm{NMR}$ ${ }^{13} \mathrm{C}\left(\mathrm{CDCl}_{3}, 77.16\right) \delta=154.26,138.56,129.55,128.67,128.16,127.87,127.79,120.78,120.11,116.58,82.39$, $55.60,49.81$.

Synthesis of 1,3-bis((2-phenyl-2H-benzo[e][1,3]oxazin-3(4H)-yl)methyl)benzene (Ph-mxda[2]ba) (Scheme 1, C, $\mathrm{R}_{1}=\mathrm{m}$-xylylene and $\mathrm{R}_{2}=\mathrm{Ph}$ )

$10.99 \mathrm{~g}$ of 2,2'-(((1,3-phenylenebis(methylene))bis(azanediyl))bis(methylene)) diphenol were dissolved in $100 \mathrm{~mL}$ of toluene. $3.36 \mathrm{~g}$ of benzaldehyde were added to the mixture, and then refluxed for $19 \mathrm{~h}$ with a Dean-Stark 
apparatus. After cooling to room temperature, solvent was removed under reduced pressure. Product was precipitated in cyclohexane and centrifugated to afford $14.28 \mathrm{~g}$ of the product as a yellow vitreous solid. Yield $=$ $86 \%$.

HRMS $\left(\mathrm{m} / \mathrm{z}\right.$, positive mode, $\left.[\mathrm{M}+\mathrm{H}]^{+}\right): \mathrm{C}_{36} \mathrm{H}_{33} \mathrm{~N}_{2} \mathrm{O}_{2}$; calculated 525.2537, found 525.2557. NMR ${ }^{1} \mathrm{H}\left(\mathrm{CDCl}_{3}, 7.26\right.$ ppm) $\delta=7.65-7.68(\mathrm{~m}, 4 \mathrm{H}), 7.37-7.41(\mathrm{~m}, 5 \mathrm{H}), 7.30-7.34(\mathrm{~m}, 5 \mathrm{H}), 7.21-7.24(\mathrm{~m}, 2 \mathrm{H}), 7.05(\mathrm{~d}, 2 \mathrm{H}), 6.90(\mathrm{~d}, 4 \mathrm{H})$, $6.01(\mathrm{~d}, 2 \mathrm{H}), 3.86(\mathrm{~m}, 8 \mathrm{H}) . \mathrm{NMR}{ }^{13} \mathrm{C}\left(\mathrm{CDCl}_{3}, 77.16\right) \delta=153.72,153.70,139.57,139.24,139.22,139.13,139.12$, $139.09,129.87,129.12,129.10,18.97,128.96,128.91,128.81,128.77,128.56,128.53,128.25,128.13,128.11$, $128.08,128.07,127.97,127.93,127.83,127.63,127.60,127.42,126.75,90.49,90.46,53.55,53.45,46.97,46.91$.

Synthesis of 3-benzyl-2-phenyl-3,4-dihydro-2H-benzo[e][1,3]oxazine (Ph-ba[2]ba) (Scheme 1, C, $\mathrm{R}_{1}=\mathrm{Bz}$ and $\mathrm{R}_{2}=$ $\mathrm{Ph})$

$1.02 \mathrm{~g}$ of 2-((benzylamino)methyl)phenol were dissolved in $20 \mathrm{~mL}$ of toluene. $0.50 \mathrm{~g}$ of benzaldehyde were added to the mixture, and then refluxed for $24 \mathrm{~h}$ with a Dean-Stark apparatus. After cooling to room temperature, solvent was removed under reduced pressure. Product was then recrystallized from toluene, leading to $0.89 \mathrm{~g}$ of a colorless powder. Yield $=54 \%$.

HRMS $\left(m / z\right.$, positive mode, $\left.[\mathrm{M}+\mathrm{H}]^{+}\right): \mathrm{C}_{21} \mathrm{H}_{19} \mathrm{NO}$; calculated 302.1539, found 302.1548. $\mathrm{NMR}{ }^{1} \mathrm{H}\left(\mathrm{CDCl}_{3}, 7.26 \mathrm{ppm}\right)$ $\delta=7.65(\mathrm{~d}, 2 \mathrm{H}), 7.27-7.40(\mathrm{~m}, 8 \mathrm{H}), 7,20(\mathrm{~m}, 1 \mathrm{H}), 7.01(\mathrm{~d}, 1 \mathrm{H}), 6.88(\mathrm{~d}, 2 \mathrm{H}), 6.00(\mathrm{~s}, 1 \mathrm{H}), 3.85(\mathrm{~m}, 4 \mathrm{H}) . \mathrm{NMR}{ }^{13} \mathrm{C}$ $\left(\mathrm{CDCl}_{3}, 77.16\right) \delta=153.72,139.21,138.96,128.89,128.77,128.53,128.50,128.09,127.92,127.85,127.28$, $126.75,120.73,119.92,116.64,90.53,53.48,46.91$.

Synthesis of 1,4-bis(3-benzyl-3,4-dihydro-2H-benzo[e][1,3]oxazin-2-yl)benzene (Ph-ba[2,2']tpa) (Scheme 1, C, $\mathrm{R}_{1}=\mathrm{Bz}$ and $\mathrm{R}_{2}=\mathrm{p}$-phenylene)

$1.01 \mathrm{~g}$ of 2-((benzylamino)methyl)phenol were dissolved in $20 \mathrm{~mL}$ of Toluene. $315 \mathrm{mg}$ of terephthalaldehyde were added to the mixture, and then refluxed for $24 \mathrm{~h}$ with a Dean-Stark apparatus. After cooling to room temperature, the product spontaneously recrystallizes as a colorless solid, and was rinsed with toluene. It was then dried under reduced pressure, leading to $576 \mathrm{mg}$ of a colorless powder. Yield $=46 \%$.

HRMS $\left(\mathrm{m} / \mathrm{z}\right.$, positive mode, $\left.[\mathrm{M}+\mathrm{H}]^{+}\right): \mathrm{C}_{36} \mathrm{H}_{33} \mathrm{~N}_{2} \mathrm{O}_{2}$; calculated 525.2537, found 525.2546. NMR ${ }^{1} \mathrm{H}\left(\mathrm{CDCl}_{3}, 7.26\right.$ ppm) $\delta=7,65(\mathrm{~s}, 1 \mathrm{H}), 7.24-7.37(\mathrm{~m}, 10 \mathrm{H}), 7.20(\mathrm{~m}, 2 \mathrm{H}), 7.01(\mathrm{~d}, 2 \mathrm{H}), 6.88(\mathrm{~d}, 2 \mathrm{H}), 5.98(\mathrm{~d}, 2 \mathrm{H}), 3.84(\mathrm{~m}, 8 \mathrm{H}) . \mathrm{NMR}$ ${ }^{13} \mathrm{C}\left(\mathrm{CDCl}_{3}, 77.16\right) \delta=153.66,153.63,139.04,139.01,138.89,138.89,128.78,128.76,128.74,128.61,128.50$, $127.94,127.85,127.54,127.29,127.28,126.87,126.86,120.75,119.87,119.86,116.62,90.42,90.35,53.64$, $53.57,46.87,46.83$.

\section{Curing of benzoxazine samples}

Between 80 and $120 \mathrm{mg}$ of benzoxazine monomer is weighed in small aluminum pans, which are then inserted in an oven preheated at $200{ }^{\circ} \mathrm{C}$, for 6 hours at atmospheric pressure.

\section{Measurements}

${ }^{1} \mathrm{H}$ and ${ }^{13} \mathrm{C}$ nuclear magnetic resonance (NMR) spectra were recorded on a Bruker AC $400 \mathrm{NMR}$ spectrometer, in $\mathrm{CDCl}_{3}$ using non-deuterated residual solvent as reference.

High Resolution Mass Spectrometry measurements (HRMS) were performed on a Waters Synapt G2-S High Resolution Mass Spectrometer equipped with an ESI (electrospray) ionization source. 
Attenuated total reflectance Fourier transform infrared absorption spectroscopy (ATR-FTIR) measurements were carried out with a Nicolet 6700 spectrometer from Thermo-Scientific, equipped with a mercury-cadmium-tellurium detector, in the middle infrared range with a resolution of $4 \mathrm{~cm}^{-1}$ and 32 scans were coadded to each spectrum.

Differential Scanning Calorimetry (DSC) on a DSC-3 F200 Maia (Netzsch GmbH) equipped with an intracooler module. The atmosphere was dry nitrogen at a flow rate of $70 \mathrm{~mL} \cdot \mathrm{min}^{-1}$. The temperature sensor was calibrated with biphenyl, indium, bismuth, and $\mathrm{CsCl}$ standards at $10^{\circ} \mathrm{C} \cdot \mathrm{min}^{-1}$. High-pressure stainless-steel pans and lids (100 MPa, sealed at $3 \mathrm{~N} \cdot \mathrm{cm}$ ) were used to prevent signal from volatile evaporation. Pans were weighed before and after the analysis to verify that there were no leaks during the analysis. Between 8 and $12 \mathrm{mg}$ of samples were weighed into the pans.

Thermogravimetric analysis (TGA) was performed with a TGA-3 libra (Netzsch GmbH). Between 10 and $12 \mathrm{mg}$ of monolithic sample was weighed in platinum pans. The atmosphere was $40 \mathrm{~mL} \cdot \mathrm{min}^{-1}$ nitrogen. The heating rate was $10^{\circ} \mathrm{C} \cdot \mathrm{min}^{-1}$ to monitor the thermal performances of cured resins from room temperature (RT) to $900{ }^{\circ} \mathrm{C}$.

The Py-GC/MS analytical setup consisted of an oven pyrolyzer connected to a GC/MS system. A Pyroprobe 5000 pyrolyzer (CDS Analytical) was used to pyrolyze the samples in a helium environment. This pyrolyzer is supplied with an electrically heating platinum filament. One coil probe enables the pyrolysis of samples (less than $1 \mathrm{mg}$ ) placed in quartz tube between two pieces of quartz wool. The sample was successively heated at 200, 300, 400, 500,600 and $900^{\circ} \mathrm{C}$. Each temperature was held for $15 \mathrm{~s}$ before gases were drawn to the gas chromatograph for $5 \mathrm{~min}$. The pyrolysis interface was coupled to a 450-GC gas chromatograph (Varian) by means of a transfer line heated at $270{ }^{\circ} \mathrm{C}$. In this oven the initial temperature of $70^{\circ} \mathrm{C}$ was held for $0.2 \mathrm{~min}$, and then raised to $310^{\circ} \mathrm{C}$ at $10^{\circ} \mathrm{C} \cdot \mathrm{min}^{-1}$. The column is a Varian Vf-5 ms capillary column $(30 \mathrm{~m} \times 0.25 \mathrm{~mm})$ and helium $\left(1 \mathrm{~mL} \cdot \mathrm{min}^{-1}\right)$ was used as the carrier gas; a split ratio was set to 1:50. The gases were introduced from the GC transfer line to the ion trap analyzer of the 240-MS mass spectrometer (Varian) through the direct-coupled capillary column. Identification of the products was achieved comparing the observed mass spectra to the American National Institute of Standards and Technology mass spectral library.

Solid content was evaluated for all monomers after curing at $200^{\circ} \mathrm{C}$. For each monomer, 6 samples were weighed before and after curing program, in order to determine the residual solid content. Results are displayed as a mean for 6 samples with $1 \sigma$ standard-deviation.

Insoluble fraction was determined by plunging cured samples in $10 \mathrm{~mL}$ of dichloromethane in sealed vials, for 48 $\mathrm{h}$ at room temperature. Samples were then dried 24 hours under vacuum and weighed in order to determine the insoluble content. Results are displayed as a mean of at least 3 samples with $1 \sigma$ standard deviation.

\section{Nomenclature}

According to the benzoxazine abbreviation proposed by Ohashi et al., ${ }^{19}$ the first letters represent the phenolic moiety, "Ph" being the phenol, after the hyphen is represented the amine moiety, "ba" symbolizing the benzylamine, and mxda the meta-xylylenediamine. The square brackets are used to precise the position where the oxazine ring is substituted, and finally, after those brackets is displayed the abbreviation of the aldehyde, i.e. "ba" stands for benzaldehyde and tpa for terephthalaldehyde. Thus, benzylamine and benzaldehyde based monobenzoxazine is described as Ph-ba[2]ba, meta-xylylenediamine and benzaldehyde based bisbenzoxazine is

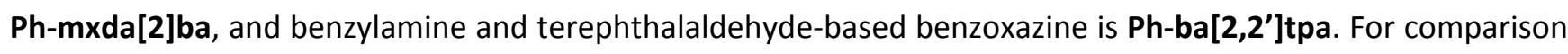
purpose, one formaldehyde-based benzoxazine was synthesized with the same method from meta- 
xylylenediamine, abbreviated Ph-mxda, this structure having been described first by F. Setiabudi from Huntsmann in a patent. ${ }^{21}$

\section{Results and discussion}

\section{Monomers synthesis and characterization}

All formaldehyde-free benzoxazines have been synthesized according to the 3-step method developed by Ronda et al., as illustrated in Scheme 1. First, salicylaldehyde was reacted with a stoichiometric amount of selected amine (1:1), in order to form the corresponding imine $\mathbf{A}$ (which was isolated for characterization purpose). Then, subsequent imine was reduced by sodium borohydride in order to get the aminomethylphenol B. Azaacetalisation, i.e. aromatic aldehyde condensation with aminomethylphenol, resulted in the desired 2substituted 1,3-benzoxazine $\mathbf{C}$. Three formaldehyde-free benzoxazines have been successfully synthesized with good yields: a monobenzoxazine based on benzylamine and benzaldehyde $\left(R_{1}=-C_{2} P h\right.$ and $\left.R_{2}=P h\right), a$ bisbenzoxazine synthesized from meta-xylylenediamine and benzaldehyde $\left(\mathrm{R}_{1}=-\mathrm{CH}_{2} \mathrm{PhCH}_{2^{-}}\right.$, meta position and $\left.R_{2}=P h\right)$ and another bisbenzoxazine, based on benzylamine and a dialdehyde, terephthalaldehyde $\left(R_{1}=C_{2} P h\right.$ and $\mathrm{R}_{2}=-\mathrm{Ph}-$, para position). Previous authors used Lewis or Brønsted acids to catalyze the condensation reaction between aldehyde and imine. For instance, Tang et al. studied the aza-acetalization of aromatic aldehydes with catalysts such as boron trifluoride ${ }^{22}$, stain tetrachloride, ${ }^{23,24}$ trimethylsilyl chloride, ${ }^{25,26}$ and other Lewis or Brønsted acids. They showed in overall that the nucleophilicity of the amine moiety is a key-parameter of this reaction. ${ }^{27}$ Ohashi et al. used a Brønsted acid catalyst for the synthesis of bisbenzoxazine from $p$ phenylenediamine. ${ }^{19}$ It shall be noted however that steric parameters have a strong influence on the amine reactivity, especially for secondary amines. ${ }^{28}$ In our case, we did not use any catalyst since we obtained the desired bisbenzoxazine structures in reasonable time scales $(\leq 26 \mathrm{~h})$ with good yields. 
${ }^{1} \mathrm{H}$ NMR spectra are displayed in Figure 1-a and in Figure S1-S4, of the supporting information. In formaldehydebased benzoxazine, characteristic peak of the $\mathrm{O}-\mathrm{CH}_{2}-\mathrm{N}$ benzoxazine ring is observed as a singlet at $4.89 \mathrm{ppm}$ whereas methylene groups of the oxazine ring or from the benzylic amine residue appear at 3.98 and $3.94 \mathrm{ppm}$. For formaldehyde-free benzoxazine, the characteristic peak resulting from the formation of the heterocycle i.e. O-CH-N proton, gives a singlet at $6.00 \mathrm{ppm}$ for Ph-ba[2]ba, whereas methylene groups display more complex multiplicities. Since they are constrained in the heterocycle, methylene protons from the ring are not equivalent, and should appear as a doublet. ${ }^{29}$ Moreover, the formation of the oxazine ring generates a stereocenter on the 2-position, thus the signal from the methylene is observed as an overlapped quadruplet with the signal of the other methylene of the benzylic amine residue, between 3.80 and $3.91 \mathrm{ppm}$. For 2-substituted bisbenzoxazine Ph-mxda[2]ba, we observe the O-CH-N signal as two singlets at 6.01 and $6.02 \mathrm{ppm}$, illustrating the presence of diastereomers (each benzoxazine ring generates asymmetry). The methylene protons signals show a complex

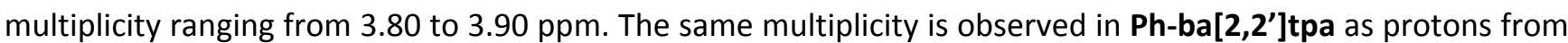
$\mathrm{O}-\mathrm{CH}-\mathrm{N}$ on the ring with two singlets at 5.97 and $5.98 \mathrm{ppm}$, and methylenes with a broad multiplet from 3.79 to $3.89 \mathrm{ppm}$. In ${ }^{13} \mathrm{C}$ NMR spectra (Figure S5-S8) methylene carbon $\mathrm{O}-\mathrm{CH}_{2}-\mathrm{N}$ for Ph-mxda is observed at $82.39 \mathrm{ppm}$. We can observe the signal of O-ArCH-N carbon on the closed ring at $90.51 \mathrm{ppm}$ for Ph-ba[2]ba. For Phmxda[2]ba, O-ArCH-N carbons appear at 90.46 and 90.49 ppm, and for Ph-ba[2,2']tpa, respectively at 90.42 ppm and $90.36 \mathrm{ppm}$. The presence of two peaks confirms the existence of diastereomers in formaldehyde-free bisbenzoxazines.

FTIR spectroscopy was performed for all the monomers and acquired spectra are displayed in Figure 1-b. Symmetric and asymmetric $\mathrm{C}_{\mathrm{Ar}}-\mathrm{O}-\mathrm{C}$ stretching bands can be respectively found at 1022 and $1218 \mathrm{~cm}^{-1} .{ }^{30}$ For the 
formaldehyde-based benzoxazine, Ph-mxda, we observe the characteristic band of oxazine ring skeletal vibration at $921 \mathrm{~cm}^{-1} .31,32$ The actual vibration assignment of this complex band is challenging and has been recently reported elsewhere. ${ }^{33} \mathrm{All}$ these characteristic bands are also observed for formaldehyde-free benzoxazines. $\mathrm{C}_{\mathrm{Ar}}-$ $\mathrm{O}-\mathrm{C}$ bands are located at 1031 and $1219 \mathrm{~cm}^{-1}$ for Ph-mxda[2]ba, 1028 and $1231 \mathrm{~cm}^{-1}$ for Ph-ba[2]ba and 1033 and $1224 \mathrm{~cm}^{-1}$ for Ph-ba[2,2']tpa. Also, the specific benzoxazine ring band related to the O-C-N bonds is located respectively at $929 \mathrm{~cm}^{-1}$ for Ph-mxda[2]ba, $932 \mathrm{~cm}^{-1}$ for Ph-ba[2]ba and $930 \mathrm{~cm}^{-1}$ for Ph-ba[2,2']tpa. It is interesting to note that this characteristic band is split into two sharp signals, compared to the formaldehydebased benzoxazine, which displays a broader unique band at $921 \mathrm{~cm}^{-1}$. This is consistent with the work of Han et al. showing that the characteristic benzoxazine related mode is affected by substitution in position 2 of the oxazine ring. ${ }^{33}$ Finally, the very similar signals between 1610 and $1450 \mathrm{~cm}^{-1}$ are attributed to the aromatic skeleton vibrations for all monomers. In addition, Mass Spectrometry was also used to complete the full characterization of the synthesized structures (Fig. S9-S14). Overall, the structural characterizations confirmed obtaining of the desired structures.

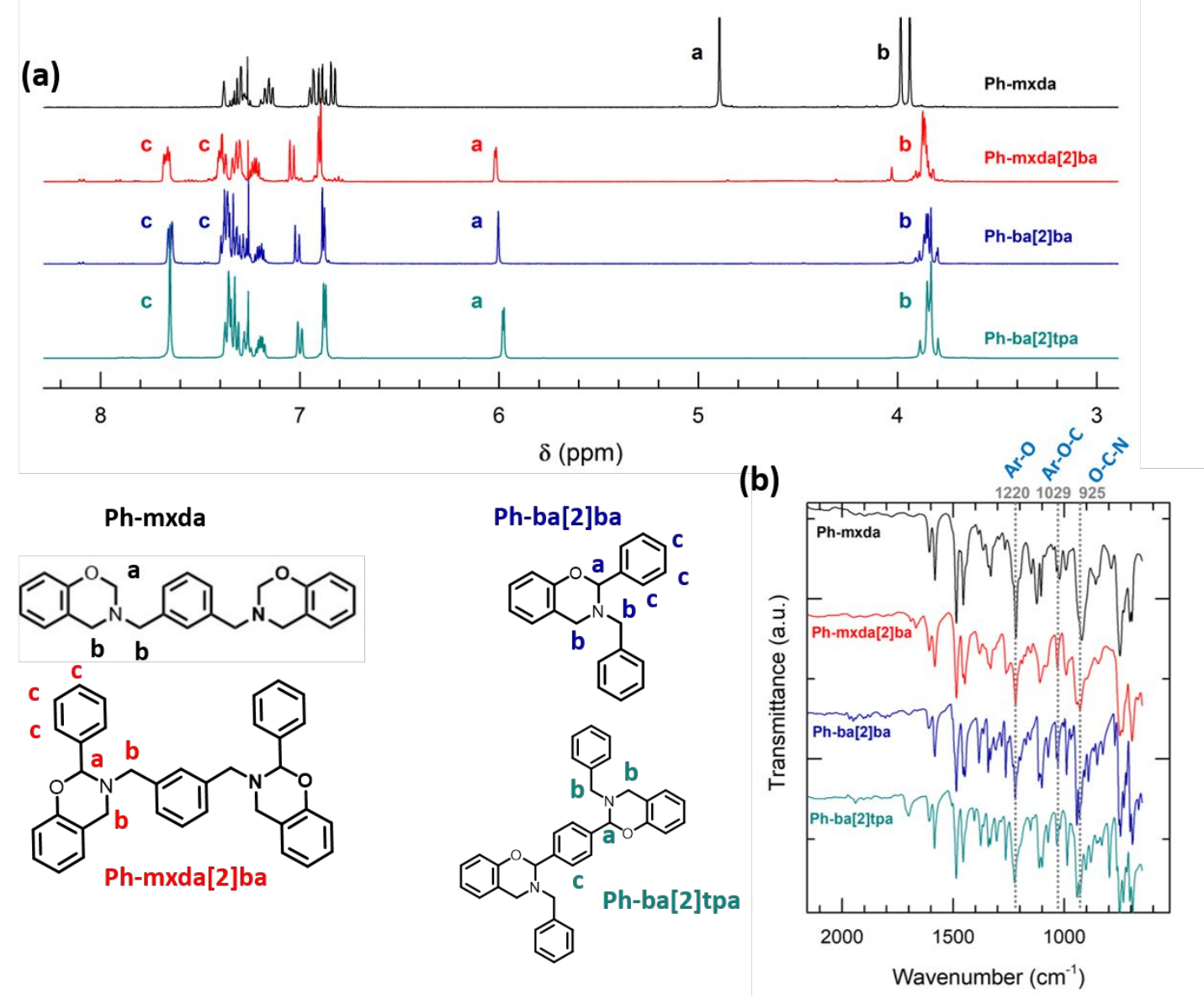

Figure 1 - (a) ${ }^{1} \mathrm{H}$ NMR spectra of Ph-mxda (1), Ph-mxda[2]ba (2), Ph-ba[2]ba (3) and Ph-ba[2,2']tpa (4) (full spectra available in SI) in chloroform-d with according structures and proton assignments. (b) FTIR spectra of benzoxazine monomers in the fingerprint region (shifted vertically).

\section{Polymerization behavior and mechanisms}

Ring-opening polymerization (ROP) has been investigated by DSC (Figure 2-a). Table 1 compares our data with the literature. First, most of the thermograms show an endothermic transition due to monomer melting. 
Interestingly, Ph-mxda and Ph-mxda[2]ba were confirmed to remain amorphous liquids, whereas the other solid benzoxazine monomers displayed a neat melting transition. Similar observation were reported for metaphenylenediamine-based benzoxazine. ${ }^{13}$ We noticed that the use of meta-substituted monomers tends to be favorable to produce desirable liquid monomers at room temperature. We also noticed that monomers having more aromatic moiety lead to higher melting temperature, e.g. $56^{\circ} \mathrm{C}$ for $\mathrm{Ph}-\mathrm{a}$ and $70-75^{\circ} \mathrm{C}$ for $\mathrm{Ph}-\mathrm{ba},(2$ rings),

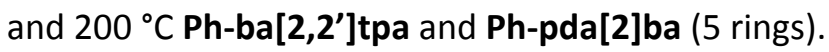

Following the melting transition, the exothermic peak is characteristic of polybenzoxazine ROP. One notes that $\mathrm{m}$-XDA benzoxazines exhibit two overlapped exotherms suggesting two reaction pathways (one single peak is observed for others). Most of our benzoxazines polymerize in the range of 200-300 ${ }^{\circ} \mathrm{C}$. However, Ph-mxda[2]ba polymerizes at a lower temperature (peak maximum at $194{ }^{\circ} \mathrm{C}$ ). Ren et al. showed that meta-oriented bisbenzoxazines have lower polymerization temperatures. ${ }^{13} \mathrm{It}$ could be attributed to the electronic configuration of meta-oriented amine which could favor the ring opening. ${ }^{20}$ This phenomenon is increased by the electronic effect of the aromatic cycle attached to the oxazine ring, which enhances the ring-opening kinetics.

Generally, bisbenzoxazines exhibit higher molar enthalpy than their monobenzoxazines counterpart, having more reactive moieties per monomer (higher functionality). In the case of monofunctional monomers, polymerization enthalpies values are higher for formaldehyde-free benzoxazine bearing a phenyl ring on the 2position. However, the trend is reversed for bisbenzoxazines and 2-substituted bisbenzoxazines, the latter have lower polymerization molar enthalpies (ca. 50\%). For instance, Ph-mxda has a polymerization enthalpy of $82 \mathrm{~kJ} \cdot \mathrm{mol}^{-1}$ and $\mathbf{P h}-\mathbf{m x d a [ 2 ] b a} 47 \mathrm{~kJ} \cdot \mathrm{mol}^{-1}$. This is confirmed when comparing Ph-pda and Ph-pda[2]ba, with respectively $51 \mathrm{~kJ} \cdot \mathrm{mol}^{-1}$ and $21 \mathrm{~kJ} \cdot \mathrm{mol}^{-1}$ of total enthalpies. Those lower polymerization enthalpies may be explained by the steric hindrance that may reduce the reactive species diffusion in 2-substituted benzoxazines compared to formaldehyde-based ones. Those results are in accordance with the work of Pereira et al., which also reported lower polymerization molar enthalpies for formaldehyde-free benzoxazines (with lower activation energies). ${ }^{20}$

Table 1 - DSC data for all benzoxazines studied. All data were generated from DSC at $10^{\circ} \mathrm{C} \cdot \mathrm{min}^{-1}$. Polymerization temperature $\left(T_{\text {polym }}\right)$ is the temperature at peak maximum)

\begin{tabular}{|c|c|c|c|c|c|c|}
\hline Entry & Aldehyde & Amine & $\mathrm{T}_{\mathrm{m}}\left({ }^{\circ} \mathrm{C}\right)$ & $\mathrm{T}_{\text {polym }}\left({ }^{\circ} \mathrm{C}\right)$ & $\begin{array}{c}\Delta \mathrm{H}_{\text {polym }}\left(\mathrm{J} \cdot \mathrm{g}^{-1}\right) \\
{\left[\mathrm{kJ} \cdot \mathrm{mol}^{-1}\right]}\end{array}$ & Ref \\
\hline $\mathrm{Ph}-\mathrm{a}$ & & & 56 & 262 & 85 [18] & 11 \\
\hline Ph-pda & & & 180 & 255 & $415[51]$ & 34 \\
\hline Ph-ba & & & 70-75 & 261 & $35[8]$ & 35 \\
\hline Ph-mxda & & & n.d. & 246 & 220 [82] & This work \\
\hline $\mathrm{Ph}-\mathrm{a}[2] \mathrm{ba}$ & & & 100 & 238 & 73 [22] & 19 \\
\hline
\end{tabular}




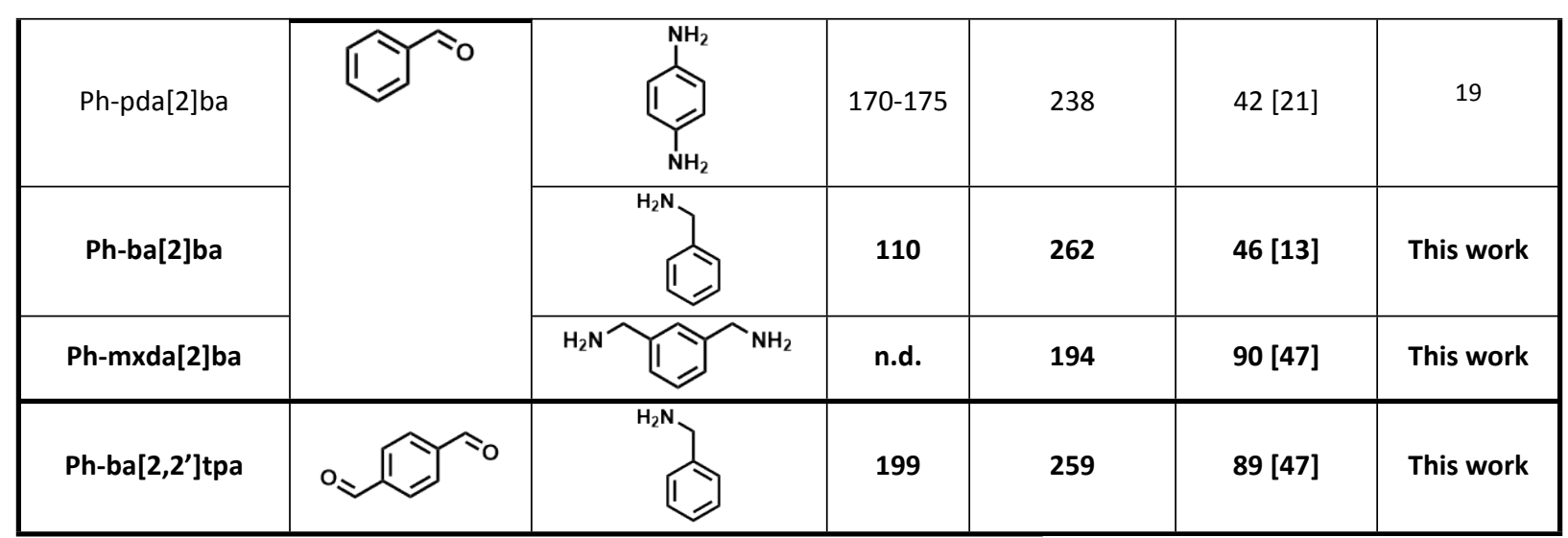

(a)

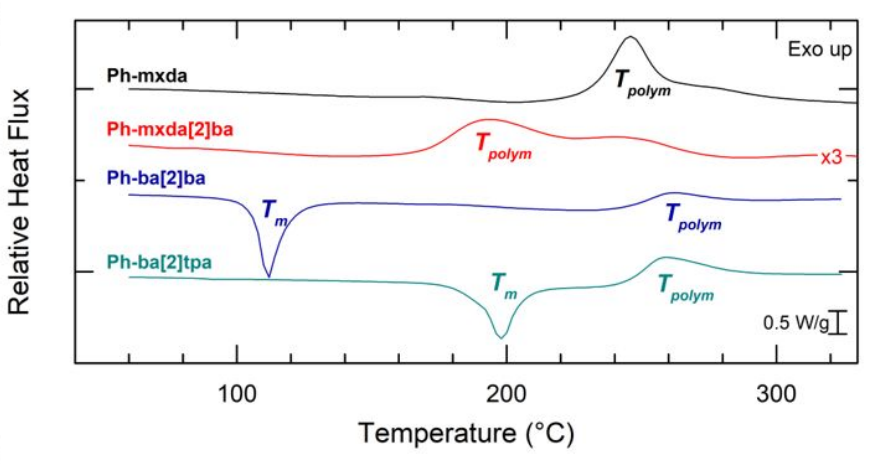

(c)

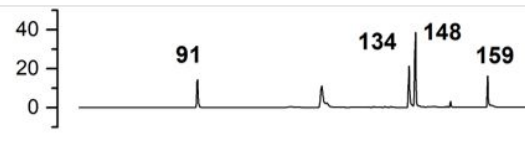

(b)
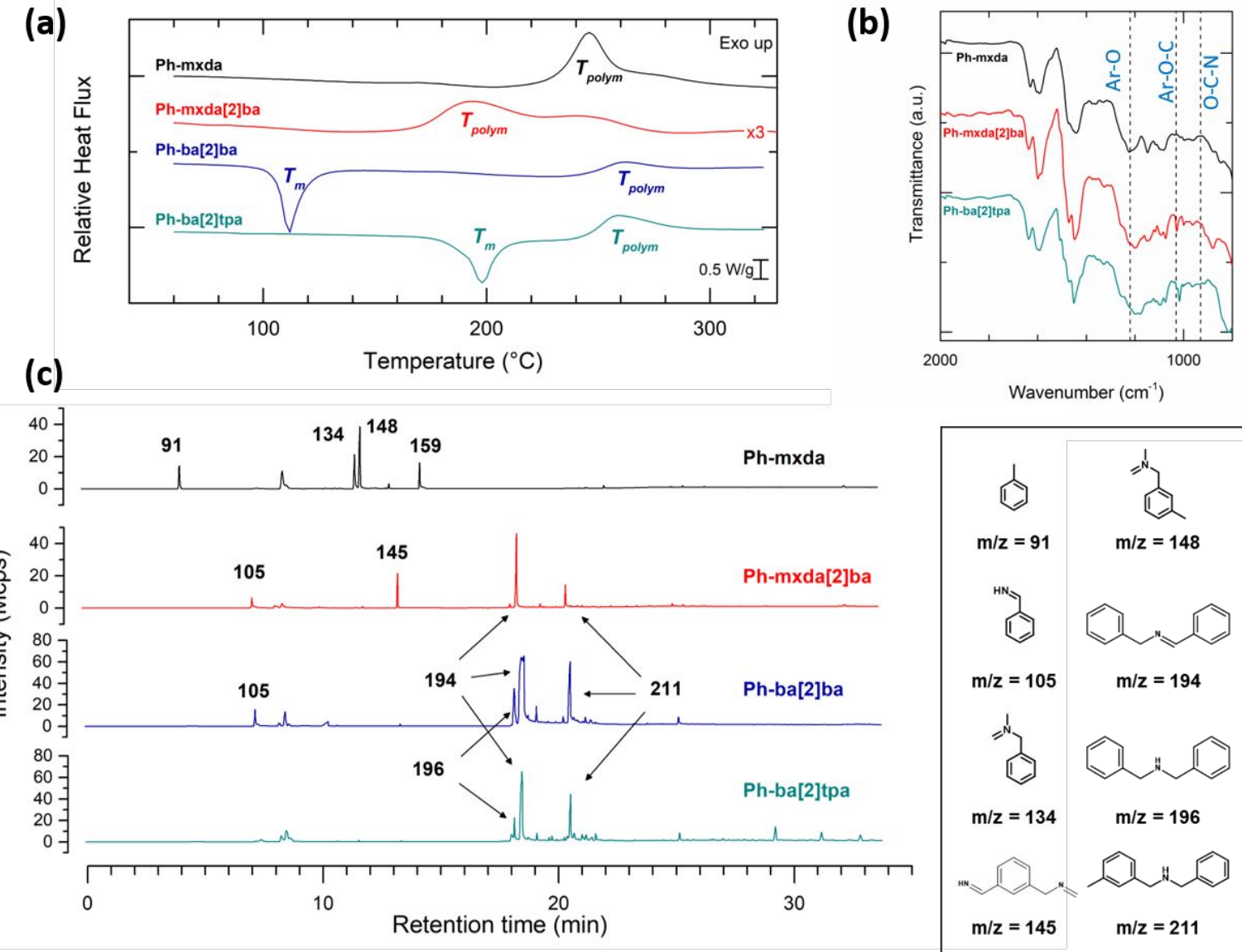

Figure 2 - (a) DSC thermograms of Ph-mxda, Ph-mxda[2]ba, Ph-ba[2] and Ph-ba[2,2']tpa at $10^{\circ} \mathrm{C} / \mathrm{min}$. (b) IR of cured polybenzoxazine between $800-2000 \mathrm{~cm}^{-1}$. (c) Py-GC/MS Chromatograms of all benzoxazines, at $200^{\circ} \mathrm{C}$, with the corresponding $\mathrm{m} / \mathrm{z}$ (Da).

After full curing at $200^{\circ} \mathrm{C}$, all polybenzoxazine were verified to be fully cross-linked, (no residual enthalpy in DSC, Figure S15). Furthermore, they were confirmed to be perfectly insoluble in a good solvent (Table S1).

FTIR spectroscopy has been used to compare the monomer and polymer structures. For all the synthesized monomers, we can observe the disappearance of the specific benzoxazine band around $920-950 \mathrm{~cm}^{-1}$ after curing, confirming the ring opening of the structures (Figure 2-b). For the formaldehyde-based benzoxazine poly(Ph-mxda), we can observe a residual band around $1220 \mathrm{~cm}^{-1}$ while the $1022 \mathrm{~cm}^{-1}$ band have disappeared, and a free $\mathrm{OH}$ band is observed as a shoulder around $3200 \mathrm{~cm}^{-1}$ (Figure S16). This observation is in line with a 
Mannich-type conformation of the cured network (Scheme 2), as demonstrated by Wang et al.. ${ }^{36}$ For 2substituted benzoxazines, Mannich-type structure is also present for poly(Ph-mxda[2]ba), as confirmed by the presence of the free $\mathrm{OH}$ band at $3200 \mathrm{~cm}^{-1}$ and the $1200 \mathrm{~cm}^{-1}$ band, while the $1028 \mathrm{~cm}^{-1}$ band decreased but did not completely disappeared, meaning that there is a mixed structure of $\mathrm{N}, \mathrm{O}$-acetal and Mannich-type. Poly(Phba[2,2']tpa) also displayed mixed structure, since there is in one hand a broad band of free $\mathrm{OH}$, showing the Mannich-type structure, and two bands at 1178 and $1017 \mathrm{~cm}^{-1}$ that are characteristics of the N,O-acetal structures. However in that case, those bands were slightly shifted compared to the monomer (1224 and 1033 $\mathrm{cm}^{-1}$ ). Bands attributed to the aromatic skeletons are still observed for all materials, in the range $1610-1450 \mathrm{~cm}^{-}$ ${ }_{1}$. The enlargement of those signals indicates additional substitution that occurred during crosslinking. Due to the low residual mass after thermal treatment, poly(Ph-ba[2]ba) could not be analyzed by FT-IR.

Sometimes described as polyaddition resin and volatile-free thermosets, it is known that ring-opening polymerization produce volatile organic compounds, such as amines or imines, which identification are clues for the comprehension in the polymerization mechanism. ${ }^{18,37,38}$ In our case, dry content was calculated by comparing the weight of a sample before and after curing at $200^{\circ} \mathrm{C}$, in order to determine the volatiles formation during polymerization. For poly(Ph-mxda), dry content is $81.0 \pm 0.7 \mathrm{wt} \%$, and for the benzaldehyde-based one, poly(Phmxda[2]ba), $81.7 \pm 0.3 \mathrm{wt} \%$ remains in the network, showing that replacing formaldehyde by benzaldehyde does not seem to impact degassing during polymerization. More volatiles are produced during the curing of Phba[2]tpa, since only $68.0 \pm 0.5 \mathrm{wt} \%$ remains in the cured samples. For the monobenzoxazine however, dry content is only $14.7 \pm 0.8 \mathrm{wt} \%$, which is consistent with the fact that this is the lightest monomer, and that monobenzoxazines are known to only produce small oligomers, that can be volatilized or degraded during the polymerization.

The structure of those volatiles can be of precious help in order to understand the curing mechanism. Direct Pyrolysis-MS has been used in the literature in order to characterize the volatile during polymerization. ${ }^{38}$ This technique has the advantage to prevent chemical recombination that could occur by trapping the volatiles in a solvent or by condensation. ${ }^{37}$ We thus performed a Pyrolysis coupled to GC/MS at $200{ }^{\circ} \mathrm{C}$, separation performed by gas chromatography allowed better MS resolutions. We observed that formaldehyde-free benzoxazines and Ph-mxda had a slightly different behavior in terms of volatile releasing. Figure 2 -c represents the chromatograms of benzoxazine monomers after pyrolysis at $200{ }^{\circ} \mathrm{C}$ for $15 \mathrm{~s}$, with associated $\mathrm{m} / \mathrm{z}$ for main peaks. Retention times, $\mathrm{m} / \mathrm{z}$ and proposed chemical structures of detected compounds are reported in Table S2 with some of the associated MS spectra (Figure S20-S22). For Ph-mxda, toluene was observed (91 Da) that could result from solvent trapped into the viscous monomer or fragmentation. Methylphenol was also observed (108 Da) and the two main peaks can be attributed to the reactive imines (134 and $148 \mathrm{Da}$ ) formed from the scission of the monomer on the oxazine ring, as reported by several publications. ${ }^{18,37-40}$ Another imine can also be found with a lower quantity, at $159 \mathrm{Da}$, corresponding to the scission on the two nitrogen atoms of the $m$-XDA residue. All MS spectra of imines or amines proposed are shown in Supporting Information file.

For all formaldehyde-free monomers, volatiles were different, except for methylphenol that was released by all samples. Retention times, $\mathrm{m} / \mathrm{z}$, proposed structures and corresponding monomers are reported in Figure 2-c and in Table S3. MS spectra are reported Figure S23-S33. Some ions were detected in the three monomers, such as imine with one or two phenyl groups (105 and $194 \mathrm{Da}$ ), or an amine with two phenyl groups that could be part of the network with crosslinking on the phenyl ring of the amine residue (211 Da). Other heavier ions were detected corresponding either to the monomer for Ph-ba[2]ba (300 Da) or opened fragments (286 or $311 \mathrm{Da}$ ) for Ph-ba[2,2']tpa. In the recent work of Pereira et al., TGA of monomers showed early weight loss, around 
$200^{\circ} \mathrm{C}^{20}$ They associated those losses to the degradation of pending alkyl chain. However, when comparing both their TGA with DSC data, we can notice that those first weight losses correspond to the ring-opening polymerization temperatures. Since the second weight loss of monomers corresponds to the one occurring for crosslinked monomers, the first weight loss corresponds to volatilization of reactive species during polymerization and not early degradation.

The polymerization mechanism that is currently the most accepted by the community implies the formation of a very reactive imine, by the ring-opening of the heterocycle on the oxygen atom (Scheme 2-a). ${ }^{39-41}$ The observation of imine compounds that are volatilized during the polymerization are in accordance with this mechanism. As they are observed both in formaldehyde-based and formaldehyde-free benzoxazine, we can conclude that the polymerization of 2-substituted benzoxazines follow the same mechanism, i.e. the ringopening occurs via the formation of a reactive imine, which is reactive towards nucleophilic ortho positions of the phenolic moiety (Scheme 2-b). The cured networked structures as analyzed by IR and the volatile structures are in accordance with the accepted polybenzoxazines mechanisms.

a)<smiles>c1ccc(CN2COc3ccccc3C2)cc1</smiles>

b)

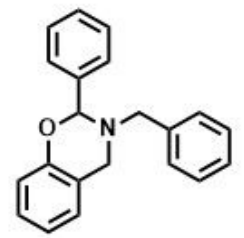

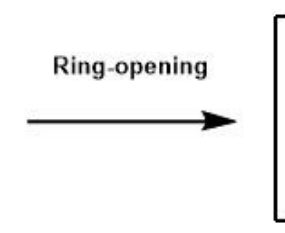

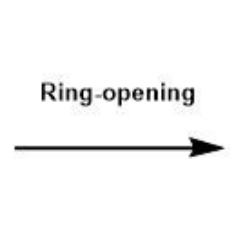

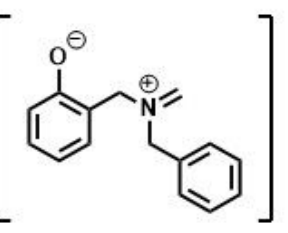

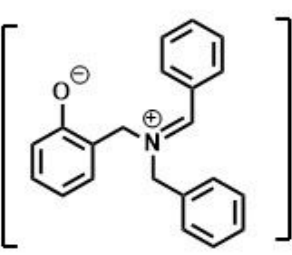

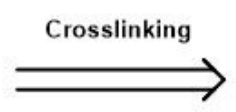

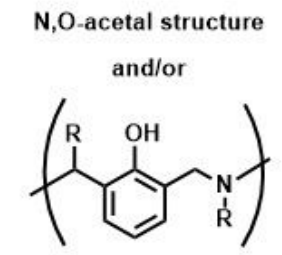

Mannich-type structure

Scheme 2 - Illustration of ring-opening of the oxazine ring in a) formaldehyde-based benzoxazines ${ }^{39-41}$ and in b) 2-phenyl substituted benzoxazine ${ }^{20}$

\section{Thermal stability and degradation}

The thermal stability has been evaluated by TGA up to $900^{\circ} \mathrm{C}$. The thermograms are shown in Figure 3-b and the results compared with literature data in Figure 3-c. ${ }^{19,35,42}$ Char yield at $800{ }^{\circ} \mathrm{C}$ and temperature at $5 \%$ weight loss $\left(T_{d 5 \%}\right)$ are usual parameters to compare the thermal stability of thermosets. All the synthesized polybenzoxazines displayed superior thermal resistance, with char yields in the range of $48-65 \%$ and $T_{d 5 \%}=310-350{ }^{\circ} \mathrm{C}$. Derivative TGA (DTG) showed the main steps of materials degradation. Degradation patterns displayed up to three steps for poly(Ph-ba[2]ba) and two main steps for all of the other samples. Early degradations around $300{ }^{\circ} \mathrm{C}$ occurred in poly(Ph-mxda) and poly(Ph-ba[2]ba), that account respectively for $3 \%$ and $4 \%$ of weight. This early degradation step is attributed to the cleavage of amine fragments ${ }^{38,43}$ and this is confirmed by the Py-GC/MS discussed below. Around $400{ }^{\circ} \mathrm{C}$, we observed DTG peaks for poly(Ph-ba[2]ba), poly(Ph-mxda[2]ba) (Figure 3-a) and poly(Ph-ba[2,2']tpa) (Figure S19), that correspond to the starting of the network degradation. Finally, for all the samples, the major weight loss happened over $500{ }^{\circ} \mathrm{C}$ according to the DTG, and corresponding to the char formation.

The degradation behavior has also been investigated using Py-GC/MS, as shown in Figure 3-c for Ph-mxda[2]ba and in Figure S17-S19 for all monomers. It shall be noted that the coherence between the TGA and Py-GC/MS results was affected by the fact that TGA uses continuous heating ramp, whereas a stepwise program was used 
for the pyrolysis. After the initial pyrolysis at $200{ }^{\circ} \mathrm{C}$, several pyrolysis steps have been performed, by heating each sample to $300,400,500,600$ and $900{ }^{\circ} \mathrm{C}$, with a cooling to room temperature between each step. We observed that for the same sample, the volatile releasing was very low compared to the curing step at $200^{\circ} \mathrm{C}$, for all benzoxazines. However as the temperature raised, the quantity of volatiles increased, which is correlated to high degradation temperature of the cured networks. In early stages of decomposition we can observe the same volatiles than during the polymerization. Those compounds could have been trapped in the network and are released over the $T_{g}$ of the material. ${ }^{44}$ They can also originate from the early degradation of the network, as it has been shown before. ${ }^{38}$ All the monomers displayed nearly the same degradation pathway, releasing at high temperature aromatic fragments such as benzene (78 Da), toluene (91 Da), xylene (106 Da), phenol (94 Da), benzonitrile (103 Da), methylphenol (108 Da), methylbenzonitrile (117 Da), phenantrenol (194 Da, Figure S34), pyrene $(208 \mathrm{Da})$ which is characteristic of charring materials, especially polybenzoxazines. ${ }^{45,46}$ The higher is the pyrolysis temperature, the lower is the molecular weight of the released compounds.

As a conclusion, even if the formaldehyde-based poly(Ph-mxda) still demonstrates maximum performances, these results prove that benzaldehyde and terephthalaldehyde are effective and promising alternatives to formaldehyde.

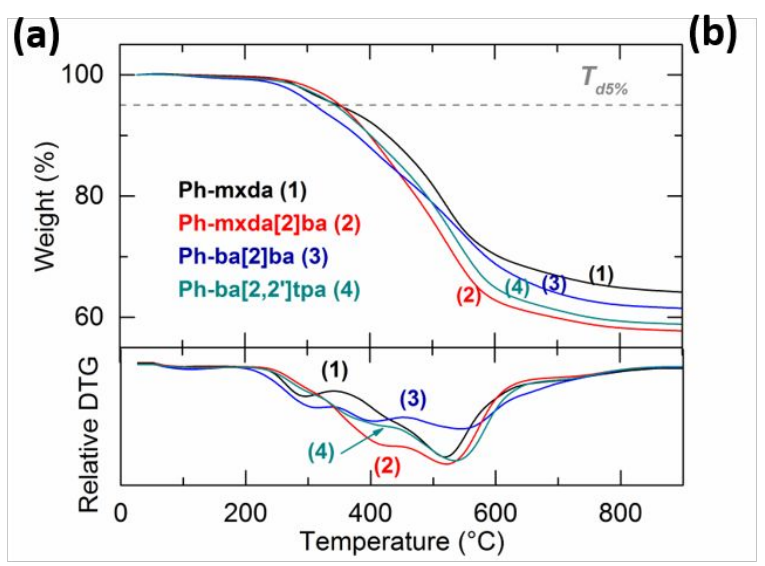

\begin{tabular}{lcc}
\hline Entry & $T_{d 5 \%}\left({ }^{\circ} \mathrm{C}\right)$ & $\begin{array}{c}\text { Char yield, } \\
\text { at } 800{ }^{\circ} \mathrm{C}(\%)\end{array}$ \\
Ph-a & 294 & 40 \\
Ph-ba & 257 & 35 \\
Ph-mxda & 349 & 65 \\
Ph-pda & 369 & 47 \\
Ph-a[2]ba & 134 & 25 \\
Ph-ba[2]ba & 311 & 62 \\
Ph-mxda[2]ba & 353 & 58 \\
Ph-pda[2]ba & 241 & 48 \\
Ph-ba[2,2']tpa & 344 & 59
\end{tabular}

Refs.

19

34

This work

41

19

This work

This work

19

This work

(c)

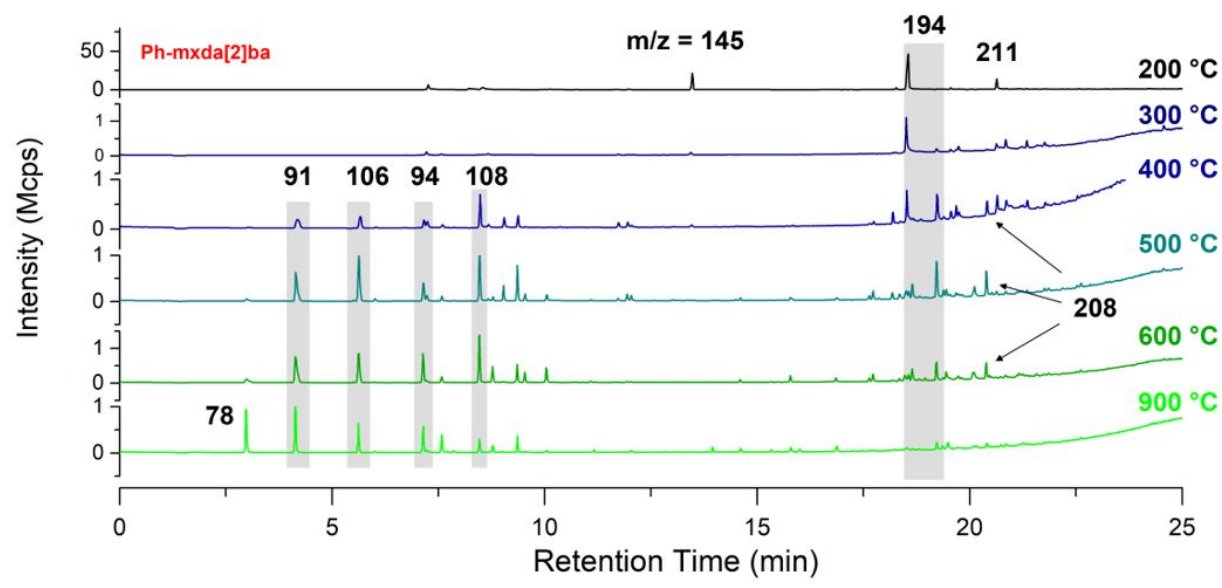

Figure 3 - (a) TGA and DTG thermograms of all synthesized benzoxazines, under nitrogen, at $10^{\circ} \mathrm{C} / \mathrm{min}$. (b) Comparison of temperature at $5 \%$ degradation and char yield of the synthesized polybenzoxazines with literature. (c) Py-GC/MS chromatograms of Ph-mxda[2]ba under the isothermal treatments ( $T$ reported next to the curves) with associated $\mathrm{m} / \mathrm{z}(\mathrm{Da})$. 
Some interesting trends can also be envisioned about the structure-thermal property relationships of salicylaldehyde benzoxazines. Fig. 4 proposes a short meta-analysis comparing our results and literature data (detailed in Figure 3-c). Owing the fact that we compare a relatively small amount of data, we hereafter outline tendencies rather than definitive conclusions. Three input categories of structures are compared (amine and aldehyde types and functionality of monomers) with a focus on char yield and $T_{d 5 \%}$ as outputs.

The amine type seems to be the key factor to increase char yields with a relatively good significance ( $p$-value $<$ 0.1 ). We observe that benzylic amines (benzylamine and $\mathrm{m}-\mathrm{XDA}$ ) gave rise to higher char yields than the aromatic aniline and p-PDA ( $+12 \%$ char yield in average). The same trends are suggested for the degradation temperatures but with a lower level of significance $\left(+70{ }^{\circ} \mathrm{C}\right)$. These higher thermal performances, that suggest higher crosslinking density, could be readily explained with the crosslinking mechanisms. As shown in Scheme 2, the imine intermediates would be more reactive in the case of aromatic amine, but it would also be more hindered, i.e. less available for nucleophilic attacks. On the other hand, because the benzylic amines are less hindered, they are supposedly more prone to react with nucleophilic moieties, i.e. the phenolates, which would finally lead to higher crosslink density and upgraded thermal performances.

The functionality of the benzoxazine monomers does not seem to be an important factor. Both mono- and bisbenzoxazine lead to similar thermal performances. In fact, increasing the functionality of the amine could lead to lower gelation time and lower volatile contents (observed in this work between benzylamine and m-XDA). Yet, comparing mono- and bis-benzoxazines, the reaction mechanisms are expected to remain the same. Both cured materials would have similar cross-linking density explaining the observed equivalent thermal performances.

From a perspective of sustainable development, it is interesting to compare formaldehyde-based to benzaldehyde-based benzoxazines. The herein compared benzaldehyde benzoxazines display lower degradation temperatures than formaldehyde ones $\left(-80^{\circ} \mathrm{C}\right)$. However, this trend is not significant, considering the dispersity of the data. In contrast, very similar average char yields are recorded for the two groups. Therefore, we consider that benzaldehyde (or terephthalaldehyde) can effectively replace the toxic formaldehyde without a significant loss of thermal resistances.

Finally, among all synthesized and discussed benzoxazines, the network Ph-mxda(2)ba is particularly attractive. With benzaldehyde rather than formaldehyde, the synthesis does not involve any CMR (Carcinogenic, Mutagenic and/or Reprotoxic) precursor (yet, to be nuanced because of the known sensitizing effects of $m$-XDA). One very interesting feature is that the monomer is liquid with no melting transition at ambient conditions, which considerably facilitates the processing conditions (along with other benzylic amine-based benzoxazine). Furthermore, Ph-mxda(2)ba possesses the lowest polymerization temperature of all systems herein studied and discussed. We envision that such monomer could be used with existing industrial processes. The advantage of using bisbenzoxazine (i.e. m-XDA rather than benzylamine) is its relatively high solid content after full curing (low VOC). Ph-mxda(2)ba displayed very good thermal performances, among the highest of the systems discussed. 
(a)
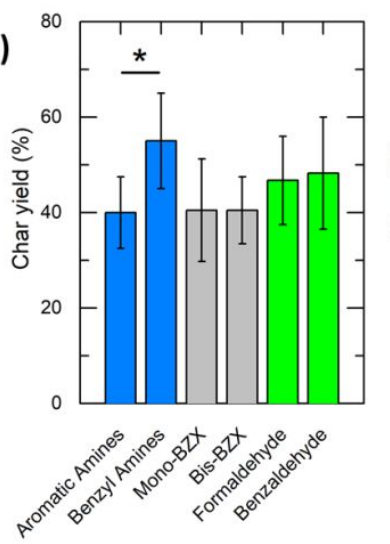

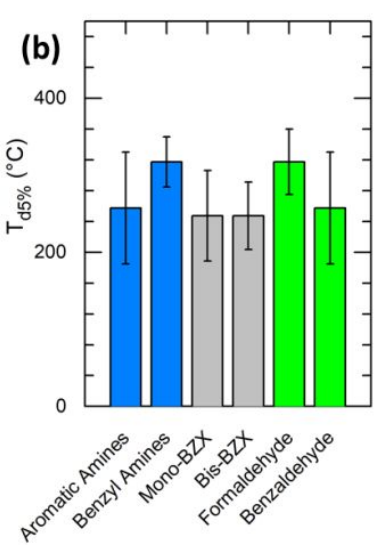

Figure 4 - Comparison of (a) char yield at $800^{\circ} \mathrm{C}$ and (b) temperature at $5 \%$ degradation of amines (blue), monomer functionality (grey) and aldehydes (green) categories. The column bar values represent the average (of the data reported in Table 3-b) along with one standard deviation as error-bars. The star marks two significantly different average values (analysis of variance: $\boldsymbol{p}$-value $=0.078$ ).

\section{Summary}

We demonstrated that the synthesis of formaldehyde-free 1,3-benzoxazine is easily accessible in 3 steps with reasonable yields. We showed that in overall, polymerization enthalpies of such monomers are lower than formaldehyde-based ones, (42-90 J.g-1 versus 35-415 J.g-1, respectively). Pyrolysis-GC/MS allowed identifying the volatile structures during thermal polymerization, which were in accordance to previously reported mechanisms for formaldehyde-based benzoxazines, leading to the hypothesis that ring-opening polymerization occurs via the same mechanisms. IR evidenced that the chemical structure of the network is similar for formaldehyde and aromatic aldehyde-based benzoxazines. Thermal stability for difunctional monomers are quite similar, leading to high char yields (58 \% for m-XDA and benzaldehyde-based benzoxazine and 59\% for benzylamine and terephthalaldehyde-based benzoxazine) and high degradation temperatures. In addition m-XDA and benzaldehyde-based structures showed lower polymerization temperature and enthalpy, with no melting point and high thermal stability. Structural characterization of cured materials revealed the same structural arrangement of the networks, leading to the conclusion that the addition of an aromatic ring on the 2-position does not affect polymerization mechanisms. Overall, we showed that we can avoid the use of formaldehyde without affecting neither the crosslinking mechanisms, the network structures nor the thermal stabilities of polybenzoxazines. With more in-depth studies on the crosslinking mechanisms of these benzoxazines and the selection of appropriate starting materials, it is expected to obtain seriously competitive and more sustainable polybenzoxazines for high performance applications.

\section{Conflicts of interest}

The authors declare no competing interest.

\section{Acknowledgements}

Authors wish to thank the French "Direction Générale de l'Armement" for the funding of the Ph.D. and the Laboratory of "Mesures Physiques" of University of Montpellier for the ESI-MS measurements. 


\section{Supporting Information}

Full ${ }^{1} \mathrm{H}$ and ${ }^{13} \mathrm{C}$ NMR spectra, ESI-HRMS of monomers, dry contents and insoluble fractions of cured materials, DSC of cured samples and Py-GC/MS chromatograms and mass spectra.

\section{References}

(1) Takeichi, T.; Kawauchi, T.; Agag, T. High Performance Polybenzoxazines as a Novel Type of Phenolic Resin. Polym. J. 2008, 40 (12), 1121-1131. https://doi.org/10.1295/polymj.PJ2008072.

(2) Ghosh, N. N.; Kiskan, B.; Yagci, Y. Polybenzoxazines-New High Performance Thermosetting Resins: Synthesis and Properties. Prog. Polym. Sci. 2007, 32 (11), 1344-1391. https://doi.org/10.1016/j.progpolymsci.2007.07.002.

(3) Yagci, Y.; Kiskan, B.; Ghosh, N. N. Recent Advancement on Polybenzoxazine-A Newly Developed High Performance Thermoset. J. Polym. Sci. Part A Polym. Chem. 2009, 47 (21), 5565-5576. https://doi.org/10.1002/pola.23597.

(4) Iguchi, D.; Salum, M. L.; Froimowicz, P. Application of Benzoxazine-Based Dimers, Oligomers, and Polymers as Chelating Agents. Macromol. Chem. Phys. 2019, 220 (1), 1800366. https://doi.org/10.1002/macp.201800366.

(5) Kiskan, B.; Ghosh, N. N.; Yagci, Y. Polybenzoxazine-Based Composites as High-Performance Materials. Polym. Int. 2011, 60 (2), 167-177. https://doi.org/10.1002/pi.2961.

(6) Iguchi, D.; Ohashi, S.; Abarro, G. J. E.; Yin, X.; Winroth, S.; Scott, C.; Gleydura, M.; Jin, L.; Kanagasegar, N.; Lo, C.; et al. Development of Hydrogen-Rich Benzoxazine Resins with Low Polymerization Temperature for Space Radiation Shielding. ACS Omega 2018, 3 (9), 11569-11581. https://doi.org/10.1021/acsomega.8b01297.

(7) Xu, S.; He, J.; Jin, S.; Tan, B. Heteroatom-Rich Porous Organic Polymers Constructed by Benzoxazine Linkage with High Carbon Dioxide Adsorption Affinity. J. Colloid Interface Sci. 2018, 509, 457-462. https://doi.org/10.1016/j.jcis.2017.09.009.

(8) Poorteman, M.; Renaud, A.; Escobar, J.; Dumas, L.; Bonnaud, L.; Dubois, P.; Olivier, M. G. Thermal Curing of Para-Phenylenediamine Benzoxazine for Barrier Coating Applications on 1050 Aluminum Alloys. Prog. Org. Coatings 2016, 97, 99-109. https://doi.org/10.1016/j.porgcoat.2016.03.026.

(9) Kiskan, B. Adapting Benzoxazine Chemistry for Unconventional Applications. React. Funct. Polym. 2018, 129 (January), 76-88. https://doi.org/10.1016/j.reactfunctpolym.2017.06.009.

(10) Holly, F. W.; Cope, A. C. Condensation Products of Aldehydes and Ketones with O-Aminobenzyl Alcohol and o-Hydroxybenzylamine. Journal of the American Chemical Society. 1944, pp 1875-1879. https://doi.org/10.1021/ja01239a022.

(11) Andreu, R.; Reina, J. A.; Ronda, J. C. Studies on the Thermal Polymerization of Substituted Benzoxazine Monomers: Electronic Effects. Journal of Polymer Science Part A: Polymer Chemistry. 2008, pp 33533366. https://doi.org/10.1002/pola.22677.

(12) Dumas, L.; Bonnaud, L.; Olivier, M.; Poorteman, M.; Dubois, P. Eugenol-Based Benzoxazine: From Straight Synthesis to Taming of the Network Properties. J. Mater. Chem. A 2015, 3 (11), 6012-6018. https://doi.org/10.1039/c4ta06636g.

(13) Ren, S.; Yang, X.; Zhao, X.; Zhang, Y.; Huang, W. An m -Phenylenediamine-Based Benzoxazine with Favorable Processability and Its High-Performance Thermoset. J. Appl. Polym. Sci. 2016, 133 (18), 43368. https://doi.org/10.1002/app.43368. 
(14) Lin, C. H.; Chang, S. L.; Hsieh, C. W.; Lee, H. H. Aromatic Diamine-Based Benzoxazines and Their High Performance Thermosets. Polymer (Guildf). 2008, 49 (5), 1220-1229.

https://doi.org/10.1016/j.polymer.2007.12.042.

(15) Imran, M.; Kiskan, B.; Yagci, Y. Concise Synthesis and Characterization of Unsymmetric 1,3-Benzoxazines by Tandem Reactions. Tetrahedron Lett. 2013, 54 (36), 4966-4969.

https://doi.org/10.1016/j.tetlet.2013.07.041.

(16) Ohashi, S.; Kilbane, J.; Heyl, T.; Ishida, H. Synthesis and Characterization of Cyanate Ester Functional Benzoxazine and Its Polymer. Macromolecules 2015, 48 (23), 8412-8417.

https://doi.org/10.1021/acs.macromol.5b02285.

(17) Oie, H.; Sudo, A.; Endo, T. Synthesis of Polymers Bearing 1,3-Benzoxazine Moiety in the Side Chains from Poly(Allylamine) and Their Crosslinking Behaviors. J. Polym. Sci. Part A Polym. Chem. 2011, 49 (14), 3174-3183. https://doi.org/10.1002/pola.24754.

(18) Nalakathu Kolanadiyil, S.; Endo, T. Toward Elucidating the Role of Number of Oxazine Rings and Intermediates in the Benzoxazine Backbone on Their Thermal Characteristics. Macromolecules 2016, 49 (22), 8466-8478. https://doi.org/10.1021/acs.macromol.6b01965.

(19) Ohashi, S.; Cassidy, F.; Huang, S.; Chiou, K.; Ishida, H. Synthesis and Ring-Opening Polymerization of 2Substituted 1,3-Benzoxazine: The First Observation of the Polymerization of Oxazine Ring-Substituted Benzoxazines. Polym. Chem. 2016, 7 (46), 7177-7184. https://doi.org/10.1039/C6PY01686C.

(20) Pereira, R. C. S.; Kotzebue, L. R. V.; Zampieri, D.; Mele, G.; Mazzetto, S. E.; Lomonaco, D. Influence of Natural Substituents in the Polymerization Behavior of Novel Bio-Based Benzoxazines. Mater. Today Commun. 2019, 21 (August), 100629. https://doi.org/10.1016/j.mtcomm.2019.100629.

(21) Setiabudi, F. Thermosetting Composition. WO2010018008, 2010.

(22) Tang, Z.-L.; Wang, L.; Tan, J.-Z.; Wan, Y.-C.; Jiao, Y.-C. Synthesis and Fungicidal Activity of 1(Carbamoylmethyl)-2-Aryl-3,1-Benzoxazines. Molecules 2017, 22 (7), 1103. https://doi.org/10.3390/molecules22071103.

(23) Tang, Z.; Chen, W.; Zhu, Z.; Liu, H. Synthesis of 2,3-Diaryl-3,4-Dihydro-2H-1,3-Benzoxazines and Their Fungicidal Activities. J. Heterocycl. Chem. 2011, 48 (2), 255-260. https://doi.org/10.1002/jhet.533.

(24) Tang, Z.; Chen, W.; Zhu, Z.; Liu, H. SnCl 4 -Catalyzed Aza-Acetalization of Aromatic Aldehydes: Synthesis of Aryl Substituted 3,4-Dihydro- 2H -1,3-Benzoxazines. Synth. Commun. 2012, 42 (9), 1372-1383. https://doi.org/10.1080/00397911.2010.540691.

(25) Tang, Z.; Zhu, Z.; Xia, Z.; Liu, H.; Chen, J.; Xiao, W.; Ou, X. Synthesis and Fungicidal Activity of Novel 2,3Disubstituted-1,3-Benzoxazines. Molecules 2012, 17 (12), 8174-8185. https://doi.org/10.3390/molecules17078174.

(26) Tang, Z.; Zhu, Z.; Yan, L.; Chang, S.; Liu, H. Efficient Synthesis of 2,3-Disubstituted-1,3-Benzoxazines by Chlorotrimethylsilane-Mediated Aza-Acetalizations of Aromatic Aldehydes. J. Heterocycl. Chem. 2013, No. 1, 1116-1120. https://doi.org/10.1002/jhet.1590.

(27) Tang, Z.; Xia, Z.; Chang, S.; Wang, Z. Synthesis and Fungicidal Activity of Novel 2-Aryl-3-(1,3,4Thiadiazolyl)-6(8)-Methyl-1,3-Benzoxazines. Bioorg. Med. Chem. Lett. 2015, 25 (16), 3378-3381. https://doi.org/10.1016/j.bmcl.2015.05.010.

(28) Brotzel, F.; Chu, Y. C.; Mayr, H. Nucleophilicities of Primary and Secondary Amines in Water. J. Org. Chem. 2007, 72 (10), 3679-3688. https://doi.org/10.1021/jo062586z.

(29) Ejfler, J.; Krauzy-Dziedzic, K.; Szafert, S.; Lis, T.; Sobota, P. Novel Chiral and Achiral Benzoxazine 
Monomers and Their Thermal Polymerization. Macromolecules 2009, 42 (12), 4008-4015. https://doi.org/10.1021/ma900336m.

(30) Socrates, G. Infrared and Raman Characteristic Group Frequencies: Tables and Charts, 3rd Edition; John Wiley and Sons, 2004.

(31) Ran, Q.-C.; Zhang, D.-X.; Zhu, R.-Q.; Gu, Y. The Structural Transformation during Polymerization of Benzoxazine/FeCl3 and the Effect on the Thermal Stability. Polymer (Guildf). 2012, 53 (19), 4119-4127. https://doi.org/10.1016/j.polymer.2012.07.033.

(32) Ishida, H.; Agag, T. Handbook of Benzoxazine Resins. In Handbook of Benzoxazine Resins; Elsevier, 2011. https://doi.org/10.1016/B978-0-444-53790-4.00089-8.

(33) Han, L.; Iguchi, D.; Gil, P.; Heyl, T. R.; Sedwick, V. M.; Arza, C. R.; Ohashi, S.; Lacks, D. J.; Ishida, H. Oxazine Ring-Related Vibrational Modes of Benzoxazine Monomers Using Fully Aromatically Substituted, Deuterated, $15 \mathrm{~N}$ Isotope Exchanged, and Oxazine-Ring-Substituted Compounds and Theoretical Calculations. J. Phys. Chem. A 2017, 121 (33), 6269-6282. https://doi.org/10.1021/acs.jpca.7b05249.

(34) Rishwana, S. S.; Pitchaimari, G.; Vijayakumar, C. T. Studies on Structurally Different Diamines and Bisphenol Benzoxazines. High Perform. Polym. 2016, 28 (4), 466-478. https://doi.org/10.1177/0954008315587125.

(35) Arslan, M.; Kiskan, B.; Yagci, Y. Ring-Opening Polymerization of 1,3-Benzoxazines via Borane Catalyst. Polymers (Basel). 2018, 10 (3), 239. https://doi.org/10.3390/polym10030239.

(36) Wang, Y.; Ishida, H. Cationic Ring-Opening Polymerization of Benzoxazines. Polymer (Guildf). 1999, 40 (16), 4563-4570. https://doi.org/10.1016/S0032-3861(99)00074-9.

(37) Sudo, A.; Du, L.-C.; Hirayama, S.; Endo, T. Substituent Effects of N-Alkyl Groups on Thermally Induced Polymerization Behavior of 1,3-Benzoxazines. J. Polym. Sci. Part A Polym. Chem. 2010, 48 (13), 27772782. https://doi.org/10.1002/pola.24026.

(38) Bagherifam, S.; Uyar, T.; Ishida, H.; Hacaloglu, J. The Use of Pyrolysis Mass Spectrometry to Investigate Polymerization and Degradation Processes of Methyl Amine-Based Benzoxazine. Polym. Test. 2010, 29 (4), 520-526. https://doi.org/10.1016/j.polymertesting.2010.03.003.

(39) Liu, C.; Shen, D.; Sebastián, R. M.; Marquet, J.; Schönfeld, R. Mechanistic Studies on Ring-Opening Polymerization of Benzoxazines: A Mechanistically Based Catalyst Design. Macromolecules 2011, 44 (12), 4616-4622. https://doi.org/10.1021/ma2007893.

(40) Furuncuoğlu Özaltın, T.; Catak, S.; Kiskan, B.; Yagci, Y.; Aviyente, V. Rationalizing the Regioselectivity of Cationic Ring-Opening Polymerization of Benzoxazines. Eur. Polym. J. 2018, 105, 61-67. https://doi.org/10.1016/j.eurpolymj.2018.05.024.

(41) Chutayothin, P.; Ishida, H. Cationic Ring-Opening Polymerization of 1,3-Benzoxazines: Mechanistic Study Using Model Compounds. Macromolecules 2010, 43 (10), 4562-4572. https://doi.org/10.1021/ma901743h.

(42) Shamim Rishwana, S.; Mahendran, A.; Vijayakumar, C. T. Studies on Structurally Different Benzoxazines Based on Diphenols and Diamines: Kinetics of Thermal Degradation and TG-FTIR Studies. Thermochim. Acta 2015, 618, 74-87. https://doi.org/10.1016/j.tca.2015.09.006.

(43) Li, C.; Ran, Q.; Zhu, R.; Gu, Y. Study on Thermal Degradation Mechanism of a Cured Aldehyde-Functional Benzoxazine. RSC Adv. 2015, 5 (29), 22593-22600. https://doi.org/10.1039/C5RA00350D.

(44) Yee Low, H.; Ishida, H. Structural Effects of Phenols on the Thermal and Thermo-Oxidative Degradation of Polybenzoxazines. Polymer (Guildf). 1999, 40 (15), 4365-4376. https://doi.org/10.1016/S0032- 


\section{1(98)00656-9.}

(45) Low, H. Y.; Ishida, H. Mechanistic Study on the Thermal Decomposition of Polybenzoxazines: Effects of Aliphatic Amines. J. Polym. Sci. Part B Polym. Phys. 1998, 36 (11), 1935-1946. https://doi.org/10.1002/(SICI)1099-0488(199808)36:11<1935::AID-POLB15>3.0.CO;2-8.

(46) Hemvichian, K.; Kim, H. D.; Ishida, H. Identification of Volatile Products and Determination of Thermal Degradation Mechanisms of Polybenzoxazine Model Oligomers by GC-MS. Polym. Degrad. Stab. 2005, 87 (2), 213-224. https://doi.org/10.1016/j.polymdegradstab.2003.11.005. 


\section{Formaldehyde-free polybenzoxazines for high performance thermosets}

Romain Tavernier ${ }^{\mathrm{a}}$, Lérys Granadoa, Gabriel Foyer ${ }^{\mathrm{b}}$, Ghislain Davida, Sylvain Caillola, ${ }^{\mathrm{*}}$

aICGM, Univ. Montpellier, CNRS, ENSCM, Montpellier, France

${ }^{b}$ ArianeGroup, Rue de Touban, 33185 Le Haillan, France

\section{For Table of Contents use only}
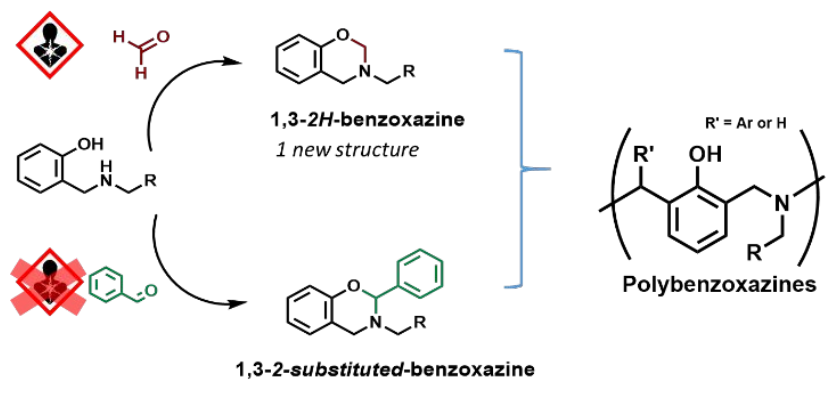